\title{
Transcatheter Aortic Valve Implantation: Our Experience and Review of the Literature
}

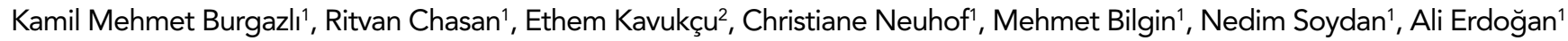 \\ 'Department of Internal Medicine, Division of Cardiology, Giessen University, Giessen, Germany \\ ${ }^{2}$ Department of Internal Medicine, Medical Center Wuppertal, Wuppertal, Germany
}

\begin{abstract}
Transcatheter Aortic Valve Implantation [TAVI] is widespread worldwide as an alternative therapy procedure to the patients suffering from severe aortic valve stenosis. However, we shouldn't forget that the conventional surgical aortic valve replacement is still the gold standard therapy for severe aortic valve stenosis. For the patients who cannot be treated conventionally because of high risk comorbid diseases and older age, TAVI is an effective alternative therapy method. The indications should be limited, concerning the high mortality rate, $10 \%$ within 30 days of intervention. Long term efficacy data are still inadequate. Although the indications are restricted to older patients with a STS score $>10$ or log-Euro Score $>20$, age is not a definite indication for this treatment. The patients should be assessed by a heart team including a non-interventional cardiologist, interventional cardiologist, cardiac anesthesiologist and cardiac surgeon according to their general status, frailty and STS- Euro score. In other words, assessment and treatment of the patient by a heart team is the main factor besides the limited power of the scoring systems. The treatment should be applied to the patients with an aortic annulus diameter between 18-27 mm and a life expectancy of at least over 1 year. The currently ongoing investigations are focused on parameters like safety, efficiency and long term reliability of TAVI. The scientific and technical developments lead to new definitions and parameters regarding the treatment indications of severe aortic valve stenosis. In this review, we present the actual data about TAVI and also our own experiences.
\end{abstract}

Key Words: TAVI, TAVI transfemoral, TAVI transapical, conventional aortic valve implantation, catheter-based aortic valve implantation

\section{Introduction}

Calcified degenerative aortic valve stenosis is the most common valvular heart disease in adults. Prevalence of aortic valve stenosis with aging is around 6-7\% over the age of 85 . Such patients bring new medical and economic burdens to the medical care system. TAVI is a new treatment method and in particular patients who are ineligible for valve replacement with the conservative surgical method or those in the high risk group, have the opportunity to benefit from this method of treatment (1-4).

Diagnosis of Aortic Valve Stenosis and Indications of TAVI

Aortic valve stenosis may not cause symptoms for a long period of time. Prognosis of the disease worsens with development of typical symptoms such as chest pain, syncope and dyspnea, or a decline in the left ventricular ejection fraction [LVEF]. Some studies report up to $80 \%$ of 2 -year mortality in symptomatic aortic valve stenosis. In general, average perioperative mortality is $4 \%$, and 3 -year survival rate is $80 \%$ following surgical aortic valve replacement procedures. The perioperative complication risk increases considerably in particular in the elderly patients with comorbid diseases such as COPD, pulmonary hypertension, renal failure, heart failure, previous cardiac surgery and consequently the perioperative mortality risk also increases. For this reason, $30 \%$ of the patients were not operated in the past, despite having first degree indication (5-8).
Symptomatic aortic valve stenosis is a first degree indication for aortic valve replacement. Valve replacement is indicated in patients with aortic valve stenosis after the development of symptoms such as dyspnea, chest pain, vertigo and syncope. Aortic stenosis patients are mostly elderly, hypertensive, obese individuals and also those with chronic lung diseases. The auscultation finding is a hard systolic murmur transmitted to the carotid arteries at the right upper sternum at the point of maximal impulse. A 'thrill" is sometimes observed at the manubrium sterni in the advanced stage. The hemodynamic significance of stenosis should be identified using echocardiography or invasive procedures due to lack of a reliable characteristic finding.

Patients have senile degenerative severe aortic valve stenosis with transthoracic echocardiographically derived criteria: mean gradient $>40 \mathrm{mmHg}$ or jet velocity greater than 4.0 $\mathrm{m} / \mathrm{s}$ or an initial aortic valve area of $<0.8 \mathrm{~cm}^{2}$.

Furthermore, patients having left ventricular function impairment with low cardiac output and patients with low aortic valve gradient are also candidates for valve replacement. However, further tests are required for such patients to confirm the indication for an aortic valve. Percutaneous aortic valve implantation is a new and favorable treatment option for these patients. Valve function can be measured by echocardiography.

Patients with advanced aortic valve stenosis and impaired left ventricular function do not comply with the above men- 
Table 1. Clinical data of patients with TAVI procedure at Giessen University

\begin{tabular}{|lccc|}
\hline Patient characteristics & $\begin{array}{c}\text { Total } \\
\mathbf{n = 2 2}\end{array}$ & $\begin{array}{c}\text { Transapical } \\
\mathbf{n = 1 5}\end{array}$ & $\begin{array}{c}\text { Transfemoral } \\
\mathbf{n = 7}\end{array}$ \\
\hline Age, year & $81( \pm 7)$ & $81( \pm 6)$ & $84( \pm 3)$ \\
BMI $\left(\mathrm{kg} / \mathrm{m}^{2}\right)$ & 26.6 & & \\
Gender, M/F & $10 / 12$ & $8 / 7$ & $2 / 5$ \\
Creatinine (mg/dL) & 1.1 & 1.11 & 1.08 \\
Renal Failure (n) & 8 & 6 & 2 \\
Diabetes Mellitus (n) & 3 & 3 & 0 \\
Hyperlipidemia (n) & 9 & 9 & 3 \\
Hypertension (n) & 16 & 13 & 3 \\
Smokers (n) & 9 & 7 & 2 \\
NYHA > III (n) & 8 & 6 & 2 \\
Coronary Artery Disease & 15 & 12 & 3 \\
Pt (n) & & & 1 \\
Atrial Fibrillation (n) & 6 & 5 & 1 \\
Pacemaker (n) post-op & 2 & 1 & 1 \\
LVEF <35\% (n) & 4 & 3 & 21.13 \\
Aortic Annulus, mm & 22.23 & 22.59 & \\
\hline
\end{tabular}

Table 2. Data on TAVI procedures performed at Giessen University

\begin{tabular}{|lccc|}
\hline Procedural data & $\begin{array}{c}\text { Total } \\
\mathbf{n = 2 2}\end{array}$ & $\begin{array}{c}\text { Transapical } \\
\mathbf{n = 1 5}\end{array}$ & $\begin{array}{c}\text { Transfemoral } \\
\mathbf{n = 7}\end{array}$ \\
\hline Contrast agent $(\mathrm{mL})$ & 124.71 & 122.67 & 140 \\
X-ray time $(\mathrm{min})$. & 9.96 & 9.96 & 17.55 \\
X-ray area (cGy/cm $\left.{ }^{2}\right)$ & 8011.76 & 8011.76 & 10000 \\
Time (min.) & 100.12 & 100.12 & 112 \\
\hline
\end{tabular}

tioned aortic valve gradient criteria. These are the patients with LVEF impairment, low cardiac output and low gradient. A significant degree of aortic stenosis is strongly confirmed particularly in these patients during transoesophageal echocardiography at the planimetry measurement. Dobutamine stress echocardiography can be applied to differentiate pseudo-stenosis from a true stenosis and to detect sufficient and insufficient contractile reserve. This test allows prediction of a perioperative mortality risk. Since insufficient contractile reserve increases the surgical mortality up to $30 \%$ in conventional valve replacement, conventional valve replacement procedure is not applied for such patients. At this point, patients can benefit from the TAVI procedure. Protective assisting devices should be available because these patients have a higher mortality risk due to acute heart failure.

TAVI is applied as an "off label" preferential treatment approach for patients with EF $<20 \%$. However, further analyses show that such patients benefit considerably from valve implantation. Valve replacement indication for most of the centers includes the above mentioned aortic stenosis, having EF $<50 \%$ and a positive stress test in echocardiography.

\section{TAVI}

\section{Evolution of TAVI}

TAVI was initially tested on animals in the mid 1960's. In 1992, Anderson et al. performed percutaneous valve implantation in pigs. A couple of years later, Bonhoeffer et al. successfully performed the first in-human percutaneous implantation, by inserting the self-expandable valve in the pulmonary valve position. In 2002, Cribier et al. (1) inserted the first balloon-expandable valve in the aorta position, called the TAVI procedure. During subsequent years, application of percutaneous transcatheter aortic valve implantation has evolved rapidly in high risk patients. TAVI, which is being applied in various centers worldwide and the follow-up results of which are reported (around 11000 patients), can well be applied with a mortality rate of between 6-10\%, despite being a high risk intervention $(9,10)$.

\section{Material and Methods}

The TAVI procedures took place in the Coronary Angiography Center at the University Hospital of Giessen and Marburg, Campus Giessen. There were a total of 22 cases who underwent the TAVI procedure in our clinic at a mean age of $81( \pm 7)$ with an average Body Mass Index of 26, and the transapical approach was applied to 15 and the transfemoral approach to 7 of these patients. Of these 22 cases, 12 were female, 15 had Coronary Artery Disease and also 3 in the transapical approach group were Diabetes Mellitus patients. 16 were closely followed because of hypertension, 8 of them were classified as NYHA III and NYHA IV and 4 of them had a LVEF less than $35 \%$. The average aortic annulus diameter was 22, $23 \mathrm{~mm}$ (Table 1, 2).

The TAVI procedure can be used in two approaches. Through a mini thoracotomy from the cardiac apex - antegrade, and through a free preparation of femoral artery; retrograde. In our institute, we employ used both methods, although the femoral approach seems to be more advantageous in terms of complications, whereas the apical approach is the option to apply TAVI in patients who are expected to have peripheral circulation problems.

\section{How to Apply Aortic Valve Implantation}

Today, percutaneous aortic valve implantation is performed as a standard procedure in well-established centers and consists of the following steps:

1. Evaluation of the aortic root and the possible accesses, mostly with imaging techniques, during the planning phase of the intervention is required. Access from the pelvic veins is not possible with current technical devices. Transfemoral access is possible in anatomical terms and there are presently 2 types of valves accepted for use in Europe. These valves differ from each other from a technical aspect.

2. TAVI-transfemoral is an intervention performed in less than 90 minutes with mild sedation, in particular in high risk patients, without the need for intubation and local anaesthesia. The aortic valve is implanted with the retrograde approach from the femoral artery. Subsequent 
valvuloplasty allows for the positioning and implantation of the valve during "rapid pacing" (explained below). A special suture system is used for closing the artery.

3. Following the procedure, the patients should be followed in particular for high degree AV-block and local bleeding.

4. The subsequent treatment follow-up protocol is similar to the drug therapy of patients with coronary stent treatment.

\section{How to Apply TAVI}

During the TAVI procedure, the aortic valve is fixated at the tip of the catheter and moved to the aortic valve area as retrograde TAVI- transfemoral (over the arterial system) or as TAVI-transapical through antegrade mini thoracotomy. For balloon-expandable or self-expandable valves, the valve is moved to the aortic valve area and is opened there. The existing valve is not removed and remains in the body, attached to the aortic wall under the newly implanted valve $(11,12)$.

\section{TAVI-Transfemoral (Figure 1)}

In cases where vessel size is adequate $(>7 \mathrm{~mm})$, the procedure is generally performed by a puncture at the A. femoralis communis. Surgical opening of the vessel is mostly not required with the use of the percutaneous suture system (PreClosure, e.g.: ProStar XL, Abbott Vascular). Therefore, general anaesthesia is not applied in many of the cases and intervention is performed with analgo sedation (e.g. Midazolam and Propofol) under regular conditions. The major determinant of TAVI- transfemoral intervention is to make a careful puncture in the vessel at an adequate distance from the bifurcation. The evolution of the inserted cannulas provides a decrease in the vascular complications experienced in the past. A steerable catheter has been developed for the implantation of the SA-

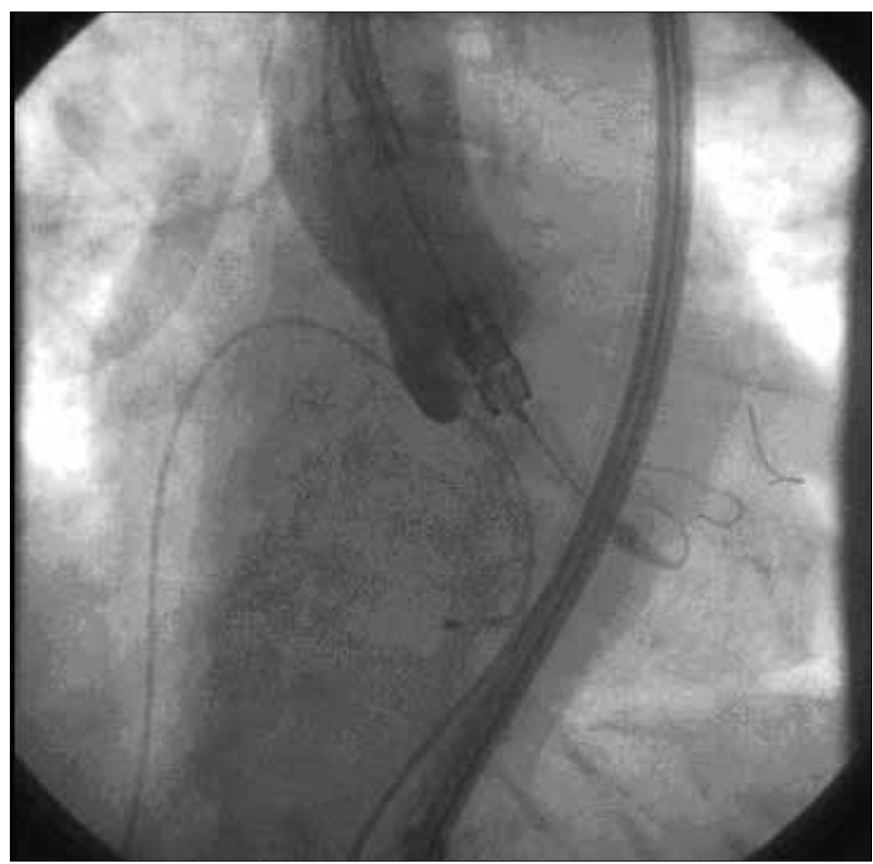

Figure 1. Positioning of Percutaneous Aortic Valve to the retrograde (transfemoral procedure) original valve position
PIEN valve to facilitate delivery from arcus aorta and the aortic valve. A 22-F access set (outer diameter $8.4 \mathrm{~mm}$ ) for the 23 $\mathrm{mm}$ prosthesis or a $24-\mathrm{F}$ access set (outer diameter $9.1 \mathrm{~mm}$ ) for $26 \mathrm{~mm}$ prosthesis are used for Edwards-SAPIEN interventions, depending on the valve sizes. A smaller 18-F-access set (outer diameter $6.5-7 \mathrm{~mm}$ ) is used for CoreValve prosthesis. Smaller and larger sized access sets will be available soon.

\section{TAVI-Transapical (Figure 2)}

Comparative studies to demonstrate the differences between TAVI-transapical access and TAVI-transfemoral access are inadequate. General anaesthesia is required during the TAVI- transapical implantation. This method is not favorable for patients with chronic lung disease such as COPD, due to the possibility for longer "weaning" period. For the patients being subject to prolonged hypoxia , the weaning effect is a syndrome in which the patients become dependent on the lung assist device after $100 \%$ oxygen, in case the respiratory function is set to the $\mathrm{pO}_{2}$ level rather than $\mathrm{pCO}_{2}$ level. Myocardial puncture is made through the left ventricular apex by way of minithoracotomy. After drilling the aortic valve in aortic valve stenosis, valvuloplasty is performed with the access set (24-F) and the prosthesis is inserted inside the aortic valve. Similar to TAVI-transfemoral intervention, "rapid pacing" is applied during implantation. The TAVI-transapical implantation method requires general anaesthesia as it is a major invasive intervention and is a method only applied when the TAVI-transfemoral approach is not appropriate for any reason.

\section{Indications / Contraindications}

Cardiologists and cardiac surgeons should cooperate in determining the indications. An adequate level of training and a fully-equipped catheterization laboratory (hybrid catheterization laboratory) is essential. It is recommended for applica-

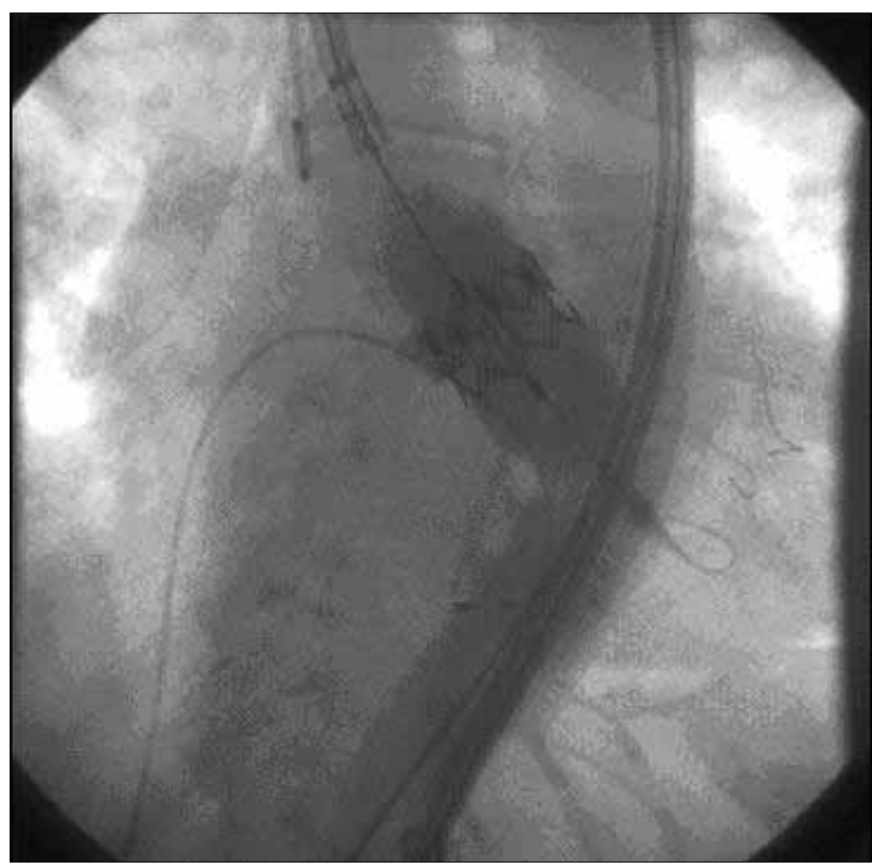

Figure 2. Implantation of percutaneous aortic valve with balloon dilatation 
tion only in centers with a cardiac surgery department since severe complications such as vessel perforation, tamponade, annulus ruptureand aortic dissection may develop in $3 \%$ of the cases (9-13).

\section{TAVI criteria:}

1. Confirmation of symptomatic aortic valve stenosis.

2. Risk-scores measured as STS (>10\%) or logEuro-Score (>20\%).

3. Evaluation of the anatomy with TEE and/or CT (17-27 $\mathrm{mm}$ ) on the basis of the annulus width.

Indication should be carefully considered for patients with a life expectancy of less than 1 year. The major criterion is to identify the width of the aortic annulus. This can most sensitively be identified with transoesophageal echocardiography [TEE] or CT techniques. TAVI should be limited to patients with an annulus width of 18-29 $\mathrm{mm}$. In the case of any coronary heart disease, the patient should be treated with percutaneous coronary intervention at least 14 days prior to the TAVI procedure. Immediate and last minute interventions should be avoided due to the risk of acute stent thrombosis and bleeding. In addition to the anatomical criteria, clinical criteria should also be considered during the decision making process for TAVI indication (12-15).

Criteria required to be evaluated in clinical terms include unusual chest malformation, porcelain aorta, previous surgical operations, comorbidities, post-radiotherapy adhesions, elderly patients at risk for surgery and patients with degenerative bio-valve. Indication should be carefully considered for patients with a life expectancy of less than 1 year.

In principle, the use of this new technology should be limited to inoperable patients or patients over 75 with a risk score STS over $10 \%$ or logEuro-Score $>20 \%$ (clinical indication class Ila).

It should be noted for patients with valvular diseases that risk scoring is not updated and is not focused on the valvular disease, because scoring is based on the data from coronary heart disease patients and is adapted to valvular diseases. Therefore, it is inadequate. Euro-score, in particular, indicates high mortality in conventional aortic valve replacement. Given such limitations, each patient should be individualized on the basis of specific risks.

There are limitations to the application of TAVI procedures, because the mortality rate within the first 30 days is $10 \%$ in all available lists for TAVI. There is no underlying rationale for the application of this procedure in low-risk patients due to the high mortality rate and, so far, this has not been attempted. Results of comparative studies between conventional procedures and TAVI are necessary for a comprehensive interpretation on the subject matter.

\section{Pre-TAVI Preparations}

Invasive diagnostic interventions are inevitable besides TEE for TAVI preparations. Detailed anatomy of the aortic root should be evaluated with aortic root angiography as part of invasive coronary imaging. Pulmonary hypertension can be ruled out with right heart catheterization and the cardiac output and valve opening area can be measured through thermo- dilution. If major stenosis is observed in the coronary vessels, a two-tiered method should be applied and initially, the vessels with coronary stenosis should be stented. TAVI should definitely not be applied within the first following 14 days. Pelvic vessels should also be imaged in addition to invasive diagnostic methods. Finally, Angio-CT (2 mm sections, multiplanar imaging) is recommended. Aortic outflow tract, ascending aorta, arcus aorta, subclavian artery, thoracic aorta, abdominal aorta, iliac arteries and femoral artery should be evaluated for calcification. It should not be applied in patients with acute systemic inflammation (sepsis, endocarditis) and also patients identified as having atrial and ventricular thrombosis. Proper anti-coagulation therapy is required for atrial fibrillation patients prior to the implantation. Patients with TAVI indication should be treated in advance with ASS $100 \mathrm{mg}$ and Clopidogrel $75 \mathrm{mg}$ and $300 \mathrm{mg}$ Clopidogrel loading dose should be administered 1 day before the implantation.

\section{Valve Types and Use of Valves}

There are two types of valves - the balloon-expandable SAPIEN-bioprosthesis (Edwards LifeSciences, Irvine, CA, USA, (15)) and the self-expandable CoreValve Revalving-system (Medtronic, Minneapolis, MN, USA, (8). There are also other different valve models at the clinical trial stage (e.g.; Jena Valve, Lotus Valve, Direct Flow, HLT, etc.)

Edwards-SAPIEN-THV is a valve with a stainless steel frame and bovine pericardial tissue. Three different sizes of 23, 26 and $29 \mathrm{~mm}$ are available in the market; TAVI-transfemoral implantation is performed with $18-\mathrm{F}, 22-\mathrm{F}$ and $24-\mathrm{F}$ cannula systems. A 33-F cannula system is required for the TAVI-transapical procedure (Figure 3). A balloon-expandable SAPIEN valve, used during TAVI-Transfemoral and TAVI-transapical implantation, should be implanted under high frequency right ventricular stimulation [rapid pacing] to allow for its stable insertion

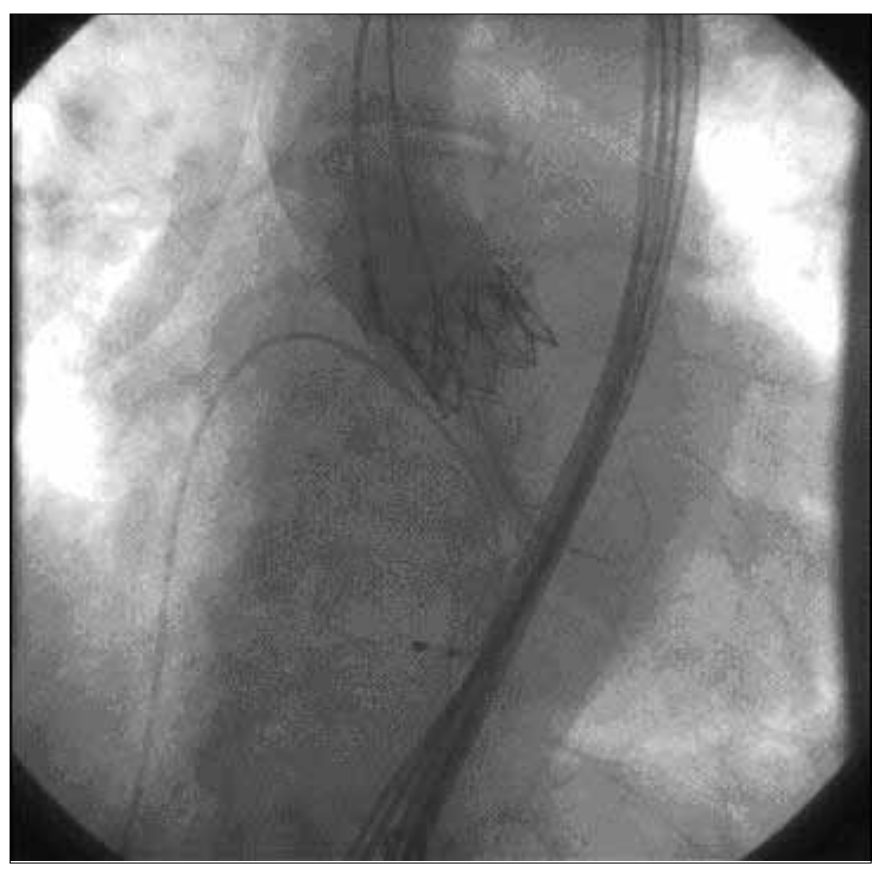

Figure 3. Checking the percutaneous valve after the balloon is deflated 
in the aortic annulus. On the other hand, the self-expandable CoreValve-prosthesis has a Nitinol frame of $5 \mathrm{~cm}$ and porcine pericardium. Since the CoreValve prosthesis is self-expandable (Self Expansion), there is no need for rapid pacing and use of balloon during the implantation. Core-Valve prosthesis is also available in two different sizes of $26 \mathrm{~mm}$ and $29 \mathrm{~mm}$, similar to the SAPIEN valve. However, larger and smaller prostheses are expected to be manufactured soon $(16,17)$.

\section{Results}

From these 22 cases, there was no mortality as a major complication at operation room. In one of the trans-apical approaches only, the incision at the apex was not self-closed. We had to actively close the apex by sewing it. Also, at one of the transfemoral approaches, we detected a leak from one side of the valve. We have electively programmed another procedure and another valve implantation into the area, and this procedure is called valve in valve. Except for this case, we have followed the patients for 3 days in our intensive care and no other major complication occurred during this period.

\section{How to Interpret TAVI Results}

Hemodynamic parameters start to change immediately after theTAVI procedure. In addition, better hemodynamic results were reported at the annulus of more stenotic aortic valves in anatomical terms (16). The average transvalvular pressure difference is under $10 \mathrm{mmHg}$ and post-intervention valve opening area reaches the level of $1.5-1.8 \mathrm{~cm}^{2}$. Unfortunately, data comparing long term results of TAVI and conventional valve replacement procedures are lacking. There is a patientprosthesis mismatch in 58 percent of the cases, mostly in the conventional aortic valve replacement procedure of a small aortic annulus. In this case, the postoperative mortality rate is around 30 percent (11). Stable hemodynamic improvements are observed at the end of the TAVI procedure in the medium term. No structural valve degeneration has been observed so far in SAPIEN and CoreValve prostheses. However, 25 percent of the patients develop prosthesis leakage. If clinically significant leakage is detected, it can be corrected by special occlusion devices. In short, the present success rate for both prostheses is around 95-98\%. The post-TAVI 30-day mortality rate is reported to be between 6-10 percent for the high risk patients in the data tables of the industrial companies (18-20).

\section{Complications}

\section{Cerebrovascular complications [CVE]}

The incidence of CVE is around 3-4 percent and is not lower than the conventional approach in TAVI interventions. Cerebrovascular complications are slightly lower after TAVItransapical implantation, with the ratio of $1-2.9 \%$. There are differences specific to both of the valve prostheses and differences in coronary stenosis (CoreValve 0.4 percent, SAPIEN 1.0-1.8 percent) due to different design structures. Vessel related complications are higher in Edwards systems by $7.4 \%$, and $2.9 \%$ in CoreValve prosthesis, as a result of size difference in TAVI-transfemoral catheterization systems (CoreValve 18-F, SAPIEN 22-24-F).
However, an absolute disadvantage of CoreValve prostheses is the considerable need for pacemaker implantation. Left bundle branch block and high degree AV-block (20-30 percent of the cases) is detected during the intervention. Pacemaker implantation is around $6.7 \%$ in conventional aortic valve surgery and $6.7-7.3 \%$ with the SAPIEN systems.

In our 22 patients, there was no operating room or hospital mortality. We observed 2 major complications: the first is in one of the trans-apical approaches, the incision at the apex did not self-close and the second is in one of the transfemoral approaches, where we detected a significant leak from one side of the valve. We did not observe any CVE.

\section{Complementary Therapy}

Post-interventional 1 day follow-up is required for patients in the intensive care unit. Follow-up at the intensive care unit may be extended in case of development of complications such as renal failure, vascular complications or bleeding. Perioperative invasive hemodynamic monitoring is required for each patient to allow for timely identification of changes in blood pressure. In particular after CoreValve implantation, transvenous pacemaker leads should definitely be available for 48 hours. A pacemaker is required in case of development of AV conduction anomalies and, in particular, postinterventional left bundle branch block (QRS >145 ms) (21). Functionality of the bioprosthesis should be checked during the follow-up by TTE and NT-proBNP, if required. Paraprosthetic leakages may sometimes not be detected by TTE and TEE methods. In case of any suspicion, angiography should be performed immediately and transvalvular hemodynamic values should be measured immediately. Oral double antiaggregant therapy should be administered. A 4-week combination therapy (100 mg Aspirin and $75 \mathrm{mg}$ Clopidogrel) is adequate for the SAPIEN valve. Combination therapy (100 mg Aspirin and $75 \mathrm{mg}$ Clopidogrel) is recommended for 6 months in CoreValve valves. $100 \mathrm{mg}$ aspirin therapy should be added to the combination therapy.

\section{Expectations}

TAVI has been applied to around 11.000 high risk patients worldwide. Significant results are expected from the PARTNER-Trial, comparing conventional valve replacement, TAVI and conservative treatment, in terms of safety, efficiency and comparison to the conventional intervention. If the trial results in favor of TAVI, its area of application would be wider. Furthermore, new generation valves and access sets are being developed by the ongoing studies with a view to decrease interventional risk in the near future and to make the TAVI procedure safer. In parallel to these developments, TAVI, presently considered to be an alternative treatment method in patients ineligible for conventional valve replacement, may take its place in the literature as an elective treatment method to be recommended as a first-line approach for high risk group patients in the near future (22-24).

\section{Conflict of Interest}

No conflict of interest was declared by the authors. 


\section{References}

1. Cribier A, Eltchaninoff H, Bash A, Borenstein N, Tron C, Bauer F, et al. Percutaneous transcatheter implantation of an aortic valve prosthesis for calcific aortic stenosis: first human case description. Circulation 2002;106:3006-8 [CrossRef]

2. Piazza N, Wenaweser P, van Gameren M, Pilgrim T, Tsikas A, Otten $A$, et al. Relationship between the logistic EuroSCORE and the Society of Thoracic Surgeons Predicted Risk of Mortality score in patients implanted with the CoreValve ReValving System - A BernRotterdam Study. Am Heart J 2010;159:323-9. [CrossRef]

3. Kalvrouziotis D, Li D, Buth KJ, Le'gare' J-F. The European System for cardiac Operative Risk Evaluation (EuroSCORE) is not appropriate for withholding surgery in high-risk patients with aortic stenosis: a retrospective cohort study. J Cardiothorac Surg 2009;4:32. [CrossRef]

4. Zajarias A, Cribier AG. Outcomes and safety of percutaneous aortic valve replacement. J Am Coll Cardiol 2009;53:1829-36. [CrossRef]

5. Piazza N, van Gameren M, Jüni P, Wenaweser P, Carrel T, Onuma $Y$, et al. A comparison of patient characteristics and 30-day mortality outcomes after transcatheter aortic valve implantation and surgical aortic valve replacement for the treatment of aortic stenosis: a two-centre study. Eurolntervention 2009;5:580-8. [CrossRef]

6. Ramaraj R, Sorrell VL. Degenerative aortic stenosis. Br Med J 2008;336:550-5. [CrossRef]

7. Lung B, Cachier A, Baron G, Messika-Zeitoun D, Delahaye F, Tornos $\mathrm{P}$, et al. Decision-making in elderly patients with severe aortic stenosis: Why are so many denied surgery? Eur Heart J 2005;26:2714-20. [CrossRef]

8. Walther T, Kempfert J, Borger MA, Fassl J, Falk V, Blumenstein $J$, et al. Human minimally invasive off-pump valve-in-a-valve implantation. Ann Thorac Surg 2008;85:1072-3. [CrossRef]

9. Frerker C, Schäfer U, Schewel D, Krüger M, Malisius R, Schneider $C$, et al. Percutaneous approaches for mitral valve interventions-a real alternative technique for standard cardiac surgery? Herz 2009;34:444-50. [CrossRef]

10. Hara H, Pedersen WR, Ladich E, Mooney M, Virmani R, Nakamura $M$, et al. Percutaneous balloon aortic valvuloplasty revisited: Time for a renaissance? Circulation 2007;115:e334-8. [CrossRef]

11. Lung B, Baron G, Butchart EG, Delahaye F, Gohlke-Bärwolf $C$, Levang OW, et al. A prospective survey of patients with valvular heart disease in Europe: The Euro Heart Survey on Valvular Heart Disease 1. Eur Heart J 2003;24:1231-43. [CrossRef]

12. Cribier A, Eltchaninoff H, Tron C, Bauer F, Agatiello C, Sebagh $L$, et al. Early experience with percutaneous transcatheter implantation of heart valve prosthesis for the treatment of endstage inoperable patients with calcific aortic stenosis. J Am Coll Cardiol 2004;43:698-703. [CrossRef]
13. Grube E, Laborde JC, Gerckens U, Felderhoff T, Sauren B, Buellesfeld $L$, et al. Percutaneous implantation of the CoreValve self-expanding valve prosthesis in high-risk patients with aortic valve disease: The Siegburg first-in-man study. Circulation 2006;114:1616-24. [CrossRef]

14. Heistad DD, Wakisaka Y, Miller J, Chu Y, Pena-Silva R. Novel aspects of oxidative stress in cardiovascular diseases. Circ J 2009;73:201-7. [CrossRef]

15. Linhartová K, Veselka J, Sterbáková G, Racek J, Topolcan $\mathrm{O}$, Cerbák R. Parathyroid hormone and vitamin $\mathrm{D}$ levels are independently associated with calcific aortic stenosis. Circ J 2008;72:245-50. [CrossRef]

16. Ross J Jr, Braunwald E. Aortic stenosis. Circulation 1968;38:61-7. [CrossRef]

17. Roberts WC, Ko JM, Filardo G. Comparison of heavier versus lighter operatively excised stenotic aortic valves in adults with aortic stenosis and implications for percutaneous aortic valve implantation without replacement. Am J Cardiol 2009;104:393405. [CrossRef]

18. Webb JG, Chandavimol M, Thompson CR, Ricci DR, Carere RG, Munt $\mathrm{BI}$, et al. Percutaneous aortic valve implantation retrograde from the femoral artery. Circulation 2006;113:842-50. [CrossRef]

19. Thomas M, Schymik G, Walther T, Himbert D, Lefèvre T, Treede $\mathrm{H}$, et al. Thirty-day results of the SAPIEN aortic bioprosthesis european outcome (SOURCE) Registry: A European registry of transcatheter aortic valve implantation using the Edwards SAPIEN valve. Circulation 2010;122:62-9. [CrossRef]

20. Piazza N, Grube E, Gerckens U, den Heijer P, Linke A, Luha O, et al. Procedural and 30-day outcomes following transcatheter aortic valve implantation using the third generation $(18 \mathrm{Fr})$ CoreValve ReValving system: Results from the multicentre, expanded evaluation registry 1-year following CE mark approval. Eurolntervention 2008;4:242-9. [CrossRef]

21. Piazza N, Onuma $Y$, Jesserun E, Kint PP, Maugenest AM, Anderson $\mathrm{RH}$, et al. Early and persistent intraventricular conduction abnormalities and requirements for pacemaking after percutaneous replacement of the aortic valve. JACC Cardiovasc Interv 2008;1:310-6. [CrossRef]

22. Fraccaro C, Napodano M, Tarantini G, Gasparetto V, Gerosa G, R, Bonato $\mathrm{R}$, et al. Expanding the eligibility for transcatheter aortic valve implantation the trans-subclavian retrograde approach using: The III generation CoreValve ReValving system. JACC Cardiovasc Interv 2009;2:828-33. [CrossRef]

23. Olsen LK, Engstrøm T, Søndergaard L. Transcatheter valve-invalve implantation due to severe aortic regurgitation in a degenerated aortic homograft. J Invasive Cardiol 2009;21:E197-200.

24. Hara H, Schwartz RS. Transcatheter aortic valve implantation in high-risk patients with severe aortic stenosis. Circulation Journal 2010;74:1513-7. [CrossRef] 